\title{
FOTOSSÍNTESE EM EUCALYPTUS SOB DIFERENTES CONDIÇÕES EDAFOCLIMÁTICAS
}

\author{
Sandro Dan Tatagiba ${ }^{1}$, José Eduardo Macedo Pezzopane ${ }^{2}$, Edvaldo Fialho dos Reis ${ }^{3}$
}

\section{RESUMO}

O objetivo deste trabalho foi avaliar as respostas fotossintéticas em um plantio clonal de eucalipto, em duas estações bem definidas: uma seca, decorrente de deficiência hídrica; e outra chuvosa, apresentando excedente hídrico no solo. O experimento foi conduzido em área de fomento da Fibria S.A, na região de Itauninhas, distrito do município de São Mateus-ES, montado em um delineamento experimental inteiramente casualizado, com dois tratamentos (estação seca e chuvosa) e 12 repetições para as trocas gasosas, fluorescência da clorofila $a$ e potencial hídrico foliar. De acordo com os resultados obtidos, foi verificado que a deficiência hídrica encontrada na estação seca foi suficiente para diminuir o teor de água nos tecidos vegetais das plantas, provocando redução em $g_{s}$ e, consequentemente, queda em $A$ e $E$. A menor abertura estomática durante estação seca contribuiu para queda na assimilação de carbono, diminuindo a produtividade potencial das plantas. A deficiência hídrica na estação seca não causou danos no aparato fotossintético do FS II, como mostrado pelo razão $F_{\mathrm{v}} / F_{\mathrm{m}}$, mas reduziu a eficiência de captação de energia luminosa pelo complexo antena do FS II, reduzindo o fluxo de elétrons, o que pode ter contribuído para a redução em $A$.

Palavras-chave: deficiência hídrica, excedente hídrico, fluorescência da clorofila $a$, trocas gasosas, eucalipto

\section{ABSTRACT}

\section{PHOTOSYNTHESIS IN EUCALYPTUS UNDER DIFFERENT ENVIRONMENTAL CONDITIONS}

The objective of this study was to evaluate the photosynthetic responses in a clonal plantation of Eucalyptus in two well-defined seasons: a drought due to water deficiency, and a rainy season with excess water in the soil. The experiment was conducted in the area of the company Fibria S.A, located in the region of Itauninhas, district of São Mateus-ES, mounted in a completely randomized design with two treatments (dry and rainy season) and 12 repetitions for gas exchange, chlorophyll a fluorescence and leaf water potential. According to the results, it was found that water stress in the dry season was sufficient to reduce the water content in plant tissues of the plants, causing a reduction in gs, and consequently decrease in A and E. The lower stomatal aperture during dry season contributed to a decrease in carbon assimilation, decreasing the productivity potential of the plants. The water shortage in the dry season caused no damage to the PS II photosynthetic apparatus, as shown by the ratio Fv/Fm, but reduced the efficiency of light energy capture by the PS II antenna complex, reducing the flow of electrons which may have contributed to reduction in A.

Keywords: water deficit, water surplus, chlorophyll fluorescence a, gas exchange, Eucalyptus

\section{Recebido para publicação em 17/11/2014. Aprovado em 11/05/2015.}

1 - Eng. Agrônomo, Pós-doutorando do Dep. de Ciências Florestais e da Madeira, CCA-UFES, E-mail: sandrodantatagiba@yahoo.com.br 2 - Eng. Florestal, Professor Adjunto do Dep. de Ciências Florestais e da Madeira, CCA-UFES, E-mail: pezzopane2007@yahoo.com.br 3 - Engenheiro Agrícola, Professor Adjunto do Departamento de Engenharia Rural, CCA-UFES, E-mail: edreis@cca.ufes.br 


\section{INTRODUÇÃO}

O monitoramento periódico das variações sazonais e diurnas das trocas gasosas, da fluorescência da clorofila $a$ e do potencial hídrico foliar pode ser associado às variações climáticas e edáficas, servindo como importante ferramenta para a compreensão de como determinada espécie ou determinado genótipo utiliza os recursos disponíveis do ambiente e de como as flutuações sazonais destes recursos afetam a produtividade primária das plantas (RYAN et al., 2010, OTTO et al., 2013).

Entender como a influência do ambiente afeta a fotossíntese tem sido foco central de estudos fisiológicos da relação entre abertura estomática e aquisição de carbono pela planta (ADDINGTON et al., 2004). O funcionamento dos estômatos constitui um comprometimento fisiológico. Quando abertos, permitem a assimilação de gás carbono, fechando-se, conservam água e reduzem o risco de desidratação (TENHUNEN et al., 1987). Segundo Larcher (2004), à medida que a disponibilidade de água no solo diminui, a taxa de transpiração decresce como resultado do fechamento dos estômatos. Esse é um dos importantes mecanismos de defesa que as plantas apresentam contra as perdas excessivas de água e eventual morte por dessecação.

Segundo Otto et al. (2013), identificar quando a temperatura, a quantidade de luz, e o suprimento de água são fatores limitantes para o crescimento é essencial para entender como o estresse hídrico pode ser amenizado. Muitos estudos foram realizados no sentido de quantificar a magnitude dos efeitos climáticos sobre a fotossíntese, avaliando-se as trocas gasosas e a produtividade, destacando-se os realizados por Tatagiba et al. (2008), Otto et al. (2013) e Valadares et al. (2014). Além desses autores, Leuning et al. (2005), estudando o fluxo de carbono e de água em um povoamento de Eucalyptus na Austrália, avaliaram a importância da sazonalidade do ambiente na produtividade, comparando a assimilação anual de carbono na estação chuvosa e seca, verificando que houve queda de $1060 \mathrm{~g} \mathrm{C} \mathrm{m}^{-2}$ ano $^{-1}$ para $360 \mathrm{~g} \mathrm{C} \mathrm{m}^{-2}$ $\mathrm{ano}^{-1}$, respectivamente. O baixo fluxo de carbono foi encontrado nos meses de menor precipitação pluviométrica.

Correia et al. (2014) indicaram que a maioria das espécies de eucalipto utilizadas em plantios comerciais apresentam um elevado consumo de água quando este recurso está facilmente disponível. Entretanto, à medida que a disponibilidade de água no solo diminui, ocorre controle expressivo da transpiração, a qual é mediada pelo fechamento parcial ou total dos estômatos, diminuindo a produtividade primária da floresta (LARCHER, 2004).

Embora as medidas de trocas gasosas sejam importantes para determinar as taxas fotossintéticas em condições específicas do ambiente, podem não ser eficientes para avaliar os efeitos fotoquímicos que ocorrem nas membranas do cloroplasto. Uma alternativa às medidas das trocas gasosas é a avaliação da eficiência fotoquímica da fotossíntese obtida por meio de variáveis da fluorescência da clorofila $a$. O rendimento da fluorescência da clorofila $a$ é uma técnica que revela o nível de excitação da energia no sistema de pigmentos que dirige a fotossíntese e fornece subsídios para estimar a inibição ou o dano no processo de transferência de elétrons no fotossistema II (FSII) (BOLHÁR-NORDENKAMPF et al., 1989). Condições de estresse ambiental podem afetar os eventos nos tilacóides, interferindo na eficiência da fotossíntese, comprometer o transporte de elétrons, e limitar a produção de ATP e $\mathrm{NADPH}_{2}$ (KRAUSE; WEISS, 1991; FLOSS et al., 2011).

Nesse sentido, torna-se evidente a necessidade de avançar o conhecimento sobre os processos fisiológicos que podem ser acionados pelas plantas de eucalipto em diferentes condições de disponibilidade hídrica. O objetivo deste trabalho foi avaliar a resposta fotossintética em um plantio clonal de eucalipto em duas diferentes condições de disponibilidade hídrica no ambiente, uma estação seca e outra chuvosa.

\section{MATERIAL E MÉTODOS}

O experimento foi conduzido na área de fomento da Fibria S.A, na região de Itauninhas, distrito do município de São Mateus, localizado no estado do 
Espírito Santo. Foi utilizado clone comercial do híbrido Eucalyptus grandis X Eucalyptus Urophylla . O plantio do clone foi realizado em maio de 2003. As plantas, nas épocas das avaliações apresentam idade de 2,5 para 3 anos, com altura e diâmetro na altura do peito (DAP) de, aproximadamente, 13,34 m e $10,25 \mathrm{~cm}$, respectivamente.

De acordo com a classificação climática de Köppen, a região é do tipo As, apresentando precipitações de outono e inverno, que ocorrem em parte do litoral nordestino. A região apresenta clima ameno ao longo do ano inteiro. A temperatura média anual fica em torno dos $24{ }^{\circ} \mathrm{C}$, variando entre $25 \mathrm{e}$ $30{ }^{\circ} \mathrm{C}$, no verão, e 19 a $21{ }^{\circ} \mathrm{C}$, no inverno. Como a precipitação pluviométrica local está na média de $1.432,8 \mathrm{~mm}$ e o índice de evapotranspiração na média de $1.395,0 \mathrm{~mm} \mathrm{ano}^{-1}$, e considerando o último quarto do século, o clima pode ser enquadrado como seco sub-úmido (RELATÓRIO FIBRIA S.A, 2006).

O solo da região é classificado como Latossolo (EMBRAPA, 1999). São solos fortes a moderadamente drenados, com pequenas variações de argila, areias e cascalhos; ausência de minerais primários (cálcio e magnésio, principalmente); presença de óxidos de alumínio ( $\mathrm{Al}$ ) e ferro $(\mathrm{Fe})$, garantindo uma textura granular relativamente porosa em relação à infiltração da água e, consequentemente, baixa capacidade de suporte nos níveis mais rasos. Assumem formas de relevo planas e suavemente onduladas, podendo chegar a profundidades superiores aos $10 \mathrm{~m}$.

Para obtenção das variáveis microclimáticas, foi instalada uma estação meteorológica automática (datalogger) no interior da floresta plantada, numa torre de acesso, com aproximadamente $37 \mathrm{~m}$ de altura, localizada próximas das áreas de estudo. $\mathrm{Na}$ estação, estavam acoplados sensores de temperatura e umidade relativa do ar, modelo HMP35C (Campbell Scientific), e um piranômetro, modelo SP-Lite (Kipp e Zonen), que media a radiação solar global. A precipitação pluviométrica era medida através de sensores modelo, TE 5255MM (Texas Eletronics).

Foi calculado o balanço hídrico da região de Itauninhas, segundo Pereira et al. (2002), proposto por Thornthwaite e Mather (1955), a fim de determinar a variação do armazenamento de água no solo ao longo do ano, caracterizando as duas estações, uma seca e outra chuvosa. Assim, possibilitou-se a identificação de períodos de deficiência e excedente hídrico no solo durante campanhas fisiológicas de campo. A evapotranspiração potencial para o cálculo do balanço hídrico foi estimada pelo método simplificado de Camargo (1962).

O período experimental foi dividido no tempo em duas campanhas fisiológicas de campo, onde foram realizadas as medições das trocas gasosas, da fluorescência da clorofila $a$ e do potencial hídrico foliar nas plantas em nas duas estações, seca e chuvosa. Durante a estação seca foi realizada a primeira campanha fisiológica de campo em dois dias consecutivos no mês de julho de 2005, enquanto, na estação chuvosa, foi realizada a segunda campanha, em dois dias consecutivos em março de 2006.

$\mathrm{Na}$ superfície de duas folhas totalmente expandidas na parte externa do terço superior da copa de seis árvores, foram medidas a fotossíntese líquida $(A)$, a condutância estomática $\left(g_{\mathrm{s}}\right)$, a transpiração $(E)$, a concentração interna de $\mathrm{CO}_{2}\left(C_{\mathrm{i}}\right)$ e estimada a eficiência instantânea no uso da água $(E U A)$, pelo quociente entre $A$ e $E$ (LARCHER, 2004). Os dados foram obtidos com auxílio de um analisador a gases infravermelho portátil (Irga), modelo Li-6400 (LICOR), utilizando fonte luminosa fixa em $1500 \mu \mathrm{mol} \mathrm{m} \mathrm{m}^{-2} \mathrm{~s}^{-1}$ de intensidade de radiação fotossinteticamente ativa. As leituras foram realizadas em cinco horários durante o dia, às 8:00, 10:00, 12:00, 14:00 e 16:00 h.

A fluorescência mínima $\left(F_{0}\right)$ máxima $\left(F_{\mathrm{m}}\right)$, e rendimento quântico efetivo do fotossistema II $\left(F_{V} /\right.$ $F_{\mathrm{m}}$ ) foram realizadas na superfície de duas folhas localizadas na parte externa do terço superior da copa de seis árvores, com auxílio de um fluorímetro (FMS2, Hansatech, Norfolk, Reino Unido). As avaliações da cinética de emissão da fluorescência da clorofila $a$, foram realizadas entre os horários de 12:30 e 13:30 h. Antes das medições, as folhas foram adaptadas ao escuro por um período de 20 min e, posteriormente, expostas a um fraco raio de medição modulado $\left(0,5 \mathrm{mmol} \mathrm{m}^{-2} \mathrm{~s}^{-1}\right.$, de $100 \mu \mathrm{S}, 1$ 
$\mathrm{Hz}$ ), para determinar $F_{0}$, quando todos os centros de reação do FS II são "abertos". Em seguida, um pulso de luz branca saturante de $2.400 \mu \mathrm{mol} \mathrm{m}^{-2} \mathrm{~s}^{-1}$ $(10 \mathrm{~Hz})$ foi aplicada durante $0,8 \mathrm{~s}$ para assegurar a emissão de $F_{\mathrm{m}}$, quando todos os centros de reação do fotossistema II (FS II) foram "fechados". A partir dessas medidas iniciais, a máximo eficiência fotoquímica das folhas de adaptação ao escuro foi estimada através da razão de fluorescência $F_{\mathrm{v}} / F_{\mathrm{m}}=$ $\left[\left(F_{\mathrm{m}}-F_{0} / F_{\mathrm{m}}\right)\right]$.

Para a determinação do potencial hídrico foliar, utilizou-se uma bomba de pressão PMS 1003 (PMS Instruments Co.), segundo Sholander et al. (1965), em duas folhas totalmente expandida de seis árvores, localizada na parte externa do terço superior do dossel. A avaliação foi realizada em um único horário durante o dia, às 4:30 h (antemanhã).

$\mathrm{O}$ delineamento experimental adotado foi inteiramente casualizado, com dois tratamentos (estação seca e chuvosa), utilizando-se 12 repetições para as trocas gasosas, fluorescência da clorofila $a$ e potencial hídrico foliar antemanhã. Os dados experimentais das trocas gasosas no horário das 10:00 h, da fluorescência da clorofia $a$ às 13:30 $\mathrm{h}$ e do potencial hídrico foliar antemanhã (4:30 h) foram submetidos à análise de variância, e quando significativas, as médias foram comparadas pelo teste de Tukey $(\mathrm{P} \leq 0.05)$ utilizando o software SISVAR $^{\circledR}$, versão 5.1 .

Realizou-se a análise de regressão linear tendo a fotossíntese $(A)$ como variável dependente $\mathrm{e}$ condutância estomática $\left(g_{\mathrm{s}}\right)$, potencial hídrico foliar antemanhã $\left(\psi_{\mathrm{h}}\right)$, fluorescência máxima $\left(F_{\mathrm{m}}\right)$ e rendimento quântico efetivo do FS II $\left(F_{\sqrt{v}} / F_{\mathrm{m}}\right)$ como variável independente para avaliar o grau de sensibilidade da fotossíntese a essas variáveis estudadas.

\section{RESULTADOS E DISCUSSÕES}

Foi realizado o cálculo do balanço hídrico durante as estações seca e chuvosa para caracterizar a condição de água prevalecente no solo (Figura 1a). Na estação seca, a pluviosidade acumulada foi de $705 \mathrm{~mm}$ (Figura 1b), apresentando um déficit hídrico de $195 \mathrm{~mm}$. Já na estação chuvosa a pluviosidade total foi de $1.205 \mathrm{~mm}$ (Figura 1b), sendo bem distribuída ao longo dos meses, e um excedente hídrico de $327 \mathrm{~mm}$ no final do período (Figura 1a).

$\mathrm{Na}$ estação seca, a temperatura média foi de $22,6{ }^{\circ} \mathrm{C}$ com a média das máximas de $30,8{ }^{\circ} \mathrm{C}$ e média das mínimas de $17,7{ }^{\circ} \mathrm{C}$, enquanto na estação seca as temperaturas média, máxima média e mínima média foram de $24,6^{\circ} \mathrm{C}, 28,7^{\circ} \mathrm{C}$, e $22^{\circ} \mathrm{C}$, respectivamente (Figura 2a). A amplitude térmica do centro de distribuição de origem do gênero Eucalyptus apresenta faixa de temperatura mínima nos meses mais frios em torno de 2 a $10{ }^{\circ} \mathrm{C}$ e de temperatura máxima nos meses mais quentes de 29 ${ }^{\circ} \mathrm{C}$ (MESKIMEN; FRANCIS, 2006).

Segundo Martins et al. (2007), a temperatura basal inferior para o desenvolvimento de Eucalyptus grandis é de $10{ }^{\circ} \mathrm{C}$ e a basal superior é de $36^{\circ} \mathrm{C}$, condições estas utilizadas durante todo o período de experimentação.

Para umidade relativa média, máxima média e mínima média na estação seca, foram encontrados valores de $77,2 \% ; 87,1 \%$ e $74,3 \%$, respectivamente. Já na estação chuvosa a umidade relativa média, máxima média e mínima média foram de $84,5 \%$; $85,3 \%$ e $81,9 \%$, respectivamente (Figura 2b). Durante todo o período, a radiação solar incidente média foi de $18,1 \mathrm{MJ} \mathrm{m}^{-2}$ dia $^{-1}$ na estação seca e $19,3 \mathrm{MJ} \mathrm{m}^{-2}$ dia $^{-1}$ na estação chuvosa (Figura 2c).
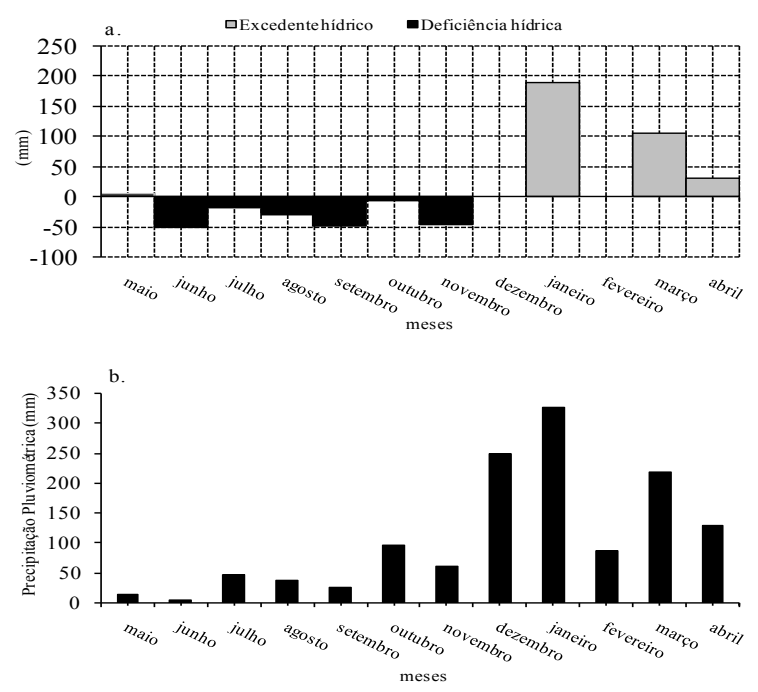

Figura 1. (a) Balanço hídrico climatológico e (b) precipitação pluviométrica durante o período experimental. 


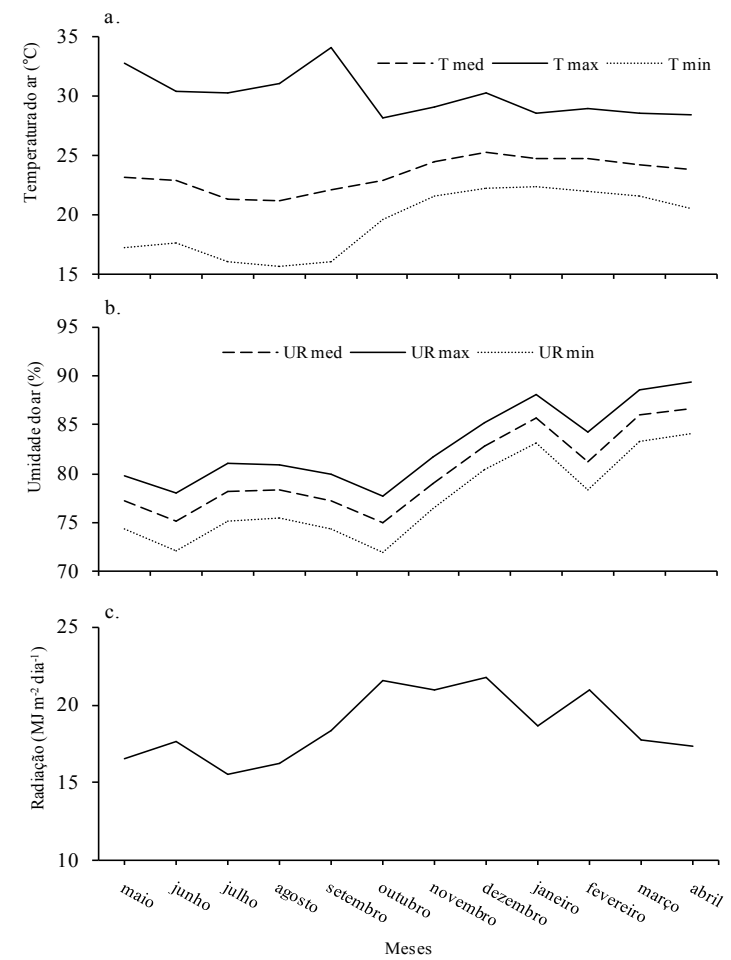

Figura 2. (a) Temperatura do ar, (b) umidade relativa do ar, (c) radiação solar incidente durante $o$ período experimental.

Nas estações seca e chuvosa foram encontradas diferenças significativas entre as médias para cada variável das trocas gasosas estudadas (Quadro 1). $\mathrm{Na}$ estação chuvosa as médias de $A, g_{\mathrm{s}}$ e $E$ foram significativamente superiores em $50,2 \%, 70,6 \%$ e $60,5 \%$, respectivamente, quando comparadas com as obtidas na estação seca. Fica evidente que a deficiência hídrica encontrada no solo durante a estação seca contribuiu para os menores valores de $A, g_{\mathrm{s}}$ e $E$, enquanto o excedente hídrico apresentado na estação chuvosa favoreceu os incrementos dessas variáveis. Os aumentos de $g_{\mathrm{s}}$ obtidos na estação chuvosa contribuíram para os incrementos de $A$ e $E$, uma vez que havia água em disponibilidade adequada no solo. Contrariamente, a deficiência hídrica na estação seca, favoreceu a redução de $g s$, diminuindo o influxo de $\mathrm{CO}_{2}$ para o interior das folhas, e, concomitantemente, o efluxo de água para o ambiente, ocasionando decréscimos nos valores de $A$ e $E$. Segundo Taiz e Zeiger (2013), o déficit hídrico reduz a fotossíntese por levar o fechamento dos estômatos, diminuindo a eficiência do processo de fixação do carbono pelas plantas; ao mesmo tempo, bloqueia a perda de água por transpiração, ajudando a reduzir a exaustão de água no solo (KOZLOWSKI; PALLARDY, 1996). Tatagiba et al. (2008), estudando a influência da deficiência hídrica em quatro genótipos de eucalipto, verificaram redução na taxa fotossintética, atribuída à menor abertura dos estômatos.

Valadares et al. (2014) também encontraram reduções de $A, g_{\mathrm{s}}$ e $E$ em cinco clones híbridos de eucalipto à medida que aumentava o turno de rega, recomendando o uso dessas variáveis das trocas gasosas como sinalizadoras do estresse hídrico em plantas.

A EUA apresentou resposta antagônica às demais variáveis de trocas gasosas (Quadro 1). Percebe-se, que a EUA foi significativamente superior na estação seca, em relação à estação chuvosa. De acordo com Larcher (2004), a EUA muda quando as condições para a difusão do $\mathrm{CO}_{2}$ ou da água são alteradas. Quando os estômatos estão totalmente abertos, a absorção de $\mathrm{CO}_{2}$ é mais limitada pela resistência de transferência do que a perda de água por transpiração. A melhor relação entre absorção de $\mathrm{CO}_{2}$ e perda de água é alcançada quando os estômatos estão parcialmente fechados. Esta situação pode ser encontrada durante a deficiência hídrica, quando os dois processos de

Quadro 1. Fotossíntese líquida $(A)$, condutância estomática $\left(g_{\mathrm{s}}\right)$, transpiração $(E)$ e eficiência no uso da água $(E U A)$, em folhas de um plantio clonal de eucalipto, na estações seca e chuvosa.

\begin{tabular}{ccccc}
\hline Estação & $\begin{array}{c}A \\
\left(\mu \mathrm{mol} \mathrm{m} \mathrm{-}^{-2} \mathrm{~s}^{-1}\right)\end{array}$ & $\begin{array}{c}g_{s} \\
\left(\mathrm{~mol} \mathrm{~m}^{-2} \mathrm{~s}^{-1}\right)\end{array}$ & $\begin{array}{c}E \\
\left(\mathrm{mmol} \mathrm{m}^{-2} \mathrm{~s}^{-1}\right)\end{array}$ & $\begin{array}{c}E U A \\
\left(\mu \mathrm{mol} \mathrm{mmol} \mathrm{mm}^{-1}\right)\end{array}$ \\
\hline Seca & $10,66 \mathrm{~b}$ & $0,143 \mathrm{~b}$ & $2,63 \mathrm{~b}$ & $4,05 \mathrm{a}$ \\
\hline Chuvosa & $21,41 \mathrm{a}$ & $0,471 \mathrm{a}$ & $6,66 \mathrm{a}$ & $3,21 \mathrm{~b}$ \\
\hline $\mathrm{CV}(\%)=$ & 13,42 & 21,54 & 15,21 & 24,34
\end{tabular}

*Médias seguidas de letras diferentes na mesma coluna diferiram entre si pelo teste de Tukey a 5\% de probabilidade. 
difusão são prontamente reduzidos e a $E U A$ atingiu os maiores valores.

Observa-se no Quadro 2 que houve diferenças significativas entre as médias para as variáveis de fluorescência de clorofila $a$ estudadas. As médias de $F_{0}$ e $F_{\mathrm{m}}$ foram significativamente superiores na estação chuvosa quando comparadas com a estação seca. A maior média de $F_{0}$ encontrada na estação chuvosa evidencia que as condições edafoclimáticas prevalecentes, como temperatura, umidade relativa do ar, radiação solar e, principalmente, o excedente hídrico no solo, contribuíram para aumento da eficiência de captação de energia luminosa pelo complexo antena do FS II, quando comparado com as condições prevalecentes na estação seca. Resultados semelhantes foram obtidos para $F_{\mathrm{m}}$, indicando que na estação seca pode ter havido deficiência na fotorredução da quinona $A\left(Q_{A}\right)$ e no fluxo de elétrons entre os fotossistemas. De Las Rivas e Barber (1997) relataram que a perda de atividade do FS II em espécies suscetíveis está provavelmente associada à diminuição da capacidade de reoxidação das quinonas, resultando em menor eficiência no transporte de elétrons para o fotossistema I (PS I).

Apesar da diferença significativa encontrada em $F_{0}$ e $F_{\mathrm{m}}$, o rendimento quântico máximo efetivo do FS II, estimado pela razão $F_{\mathrm{v}} / F_{\mathrm{m}}$, não apresentaram diferenças significativas entre as médias nas estações seca e chuvosa. $F_{\mathrm{v}} / F_{\mathrm{m}}$ é um indicador sensível do desempenho fotossintético das plantas (KRAUSE; WEIS, 1991). Alterações na $F_{\sqrt{ }} F_{\mathrm{m}}$ são atribuídas às mudanças na eficiência do quenching não fotoquímico. Segundo BolhàrNordenkampf et al. (1989), valores de $F_{\mathrm{v}} / F_{\mathrm{m}}$ entre 0,75 a 0,85 são indicativos de que as plantas submetidas a algum tipo de estresse ambiental não apresentaram, em particular, danos fotoinibitórios. Assim, os valores semelhantes de 0,81 , obtidos para $F_{\mathrm{v}} / F_{\mathrm{m}}$ nas estações seca e chuvosa, evidenciam que a deficiência hídrica no solo e as condições climáticas prevalecentes na estação seca não foram suficientes para provocar danos fotoinibitórios no aparato fotossintético do FS II.

$\mathrm{O} \psi_{\mathrm{h}}$ apresentou diferenças significativas entre as duas estações, seca e chuvosa (Quadro 2). Na estação chuvosa foram registrados maiores valores de $\psi_{h}$, em relação à estação seca. A redução do $\psi_{\mathrm{h}}$ na estação seca, causada pela deficiência hídrica do solo, sugere que a planta está sofrendo desidratação do protoplasma, podendo prejudicar os processos vitais de crescimento (LARCHER, 2004). Quando o $\psi_{\mathrm{h}}$ é reduzido, a taxa fotossintética pode ser diminuída na mesma proporção. Segundo Kozlowski e Pallardy (1996), é difícil estabelecer um $\psi_{\mathrm{h}}$ no qual a $A$ começa a decrescer porque esse valor varia com a espécie, genótipo, habitat e as condições prevalecentes no ambiente.

As diferenças da taxa fotossintética encontrada durante o curso diário entre as duas estações evidenciam que as condições climáticas de temperatura, umidade relativa do ar, radiação e principalmente de precipitação encontrada na estação chuvosa favoreceram o incremento da fotossíntese nas plantas (Figura 3). Assim, para o adequado estabelecimento de um povoamento florestal de eucalipto, torna-se necessário não só a distribuição mensal da precipitação, mas também, sua distribuição anual, já que a água é necessária durante todo o desenvolvimento da planta e é um dos fatores determinantes da produtividade.

Os valores de $A$ na estação chuvosa foram superiores em todos os horários durante o dia quando comparados com os obtidos na estação seca, encontrando maior diferença às $16: 00 \mathrm{~h}$ (Figura 3). O menor e o maior valor médio obtido na estação seca para $A$ foi de $4,12 \mu \mathrm{mol} \mathrm{m} \mathrm{m}^{-2} \mathrm{~s}^{-1}$ às 16:00 h e $16,1 \mu \mathrm{mol} \mathrm{m}^{-2} \mathrm{~s}^{-1}$ às 8:00 h. Já na estação

Quadro 2. Fluorescência mínima $\left(F_{0}\right)$, fluorescência máxima $\left(F_{\mathrm{m}}\right)$, rendimento quântico máximo do FSII $\left(F_{\mathrm{v}} / F_{\mathrm{m}}\right)$ e potencial hídrico antemanhã $\left(\psi_{\mathrm{h}}\right)$, em folhas de um plantio clonal de eucalipto, na estações seca e chuvosa.

\begin{tabular}{ccccc}
\hline Estação & $F_{0}$ & $F_{\mathrm{m}}$ & $F_{\mathrm{v}} / F_{\mathrm{m}}$ & $\psi_{\mathrm{h}}(\mathrm{MPa})$ \\
\hline Seca & $394 \mathrm{~b}$ & $2189 \mathrm{~b}$ & $0,81 \mathrm{a}$ & $-1,99 \mathrm{a}$ \\
\hline Chuvosa & $492 \mathrm{a}$ & $2696 \mathrm{a}$ & $0,81 \mathrm{a}$ & $-3,89 \mathrm{~b}$ \\
\hline $\mathrm{CV}(\%)=$ & 6,14 & 5,97 & 2,10 & 15,71 \\
\hline
\end{tabular}

*Médias seguidas de letras diferentes na mesma coluna diferiram entre si pelo teste de Tukey a $5 \%$ de probabilidade. 
chuvosa o menor e maior valor médio de $A$ foram de $19,2 \mu \mathrm{mol} \mathrm{m}^{-2} \mathrm{~s}^{-1}$ e $25,2 \mu \mathrm{mol} \mathrm{m}{ }^{-2} \mathrm{~s}^{-1}$ encontrados nos horários de 12:00 e 16:00 h, respectivamente.

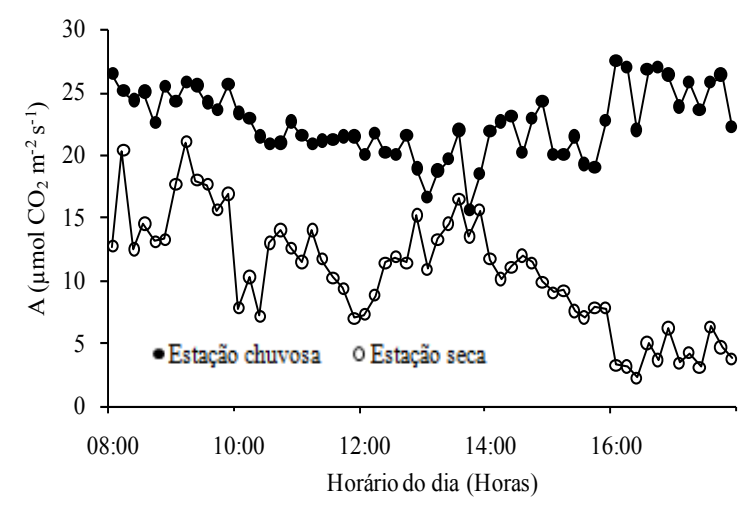

Figura 3. Fotossíntese ao longo do curso diário (às 8:00, 10:00, 12:00, 14:00 e 16:00 h), em folhas de um plantio clonal de eucalipto, durante as estações seca e chuvosa.

Os resultados de $A$ encontrados no presente trabalho na estação seca estão de acordo com os obtidos por Tatagiba et al., (2008), que verificaram em um plantio clonal de eucalipto com 36 meses de idade, $12,72 \mu \mathrm{mol} \mathrm{m} \mathrm{m}^{2} \mathrm{~s}^{-1}$. Na estação chuvosa a fotossíntese de $25,2 \mu \mathrm{mol} \mathrm{m} \mathrm{m}^{-2} \mathrm{~s}^{-1}$ apresentou valor muito próximo do encontrado por Marrichi (2009), em que a fotossíntese máxima foi de $25,7 \mu \mathrm{mol} \mathrm{m}{ }^{2}$ $\mathrm{s}^{-1}$ em plantas de eucalipto de 16 meses de idade. Entretanto, valores de fotossíntese inferiores ao presente estudo foram encontrados por Otto et al. (2013), registrando 12,5 a $16,4 \mu \mathrm{mol} \mathrm{m} \mathrm{m}^{-1}$, para quatro clones de Eucalyptus em área úmida, aos 23 meses de idade.

A relação linear encontrada entre a $A$ e $g_{\mathrm{s}}$ explica a maior taxa fotossintética na estação chuvosa (Figura 4). A fotossíntese apresentou aumento linear à medida que aumentava a condutância estomática. Entretanto, os maiores valores obtidos por $g_{\mathrm{s}}$ na estação chuvosa favoreceram incrementos em $A$, enquanto o fechamento parcial dos estômatos na condição de deficiência hídrica, durante a estação seca, contribuiu para a redução em $A$. Vários trabalhos tem relacionado redução em $A$ à decréscimos em $g_{s}$ causado pela deficiência hídrica (TATAGIBA et al., 2008; MARRICHI 2009, OTTO et al., 2013; VALADARES et al., 2014).

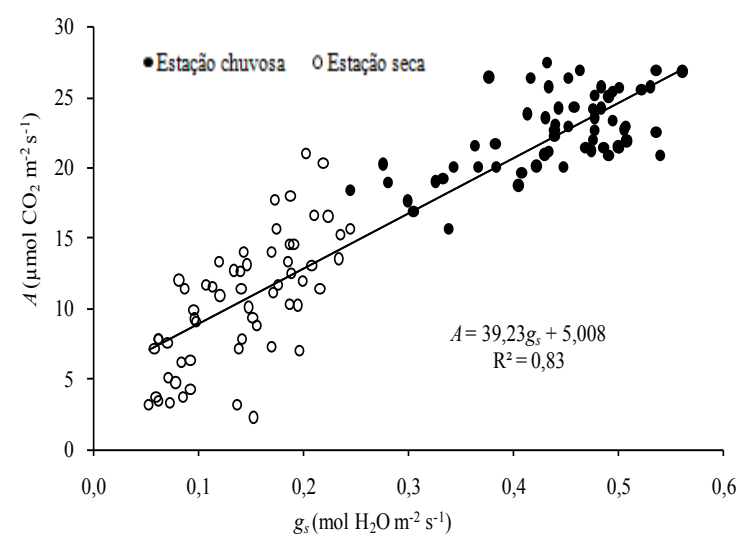

Figura 4. Regressão linear relacionando a fotossíntese $(A)$ com a condutância estomática $\left(g_{\mathrm{s}}\right)$, ao longo do período diurno (às 8:00, 10:00, 12:00, 14:00 e 16:00 h), em folhas de um plantio clonal de eucalipto, nas estações seca e chuvosa.

Na Figura 5, é apresentada a relação entre $A$ e $\psi_{\mathrm{h}}$. Nota-se, que à medida que os valores do $\psi_{\mathrm{h}}$ diminuíam, os valores de $A$ também diminuíram, indicando que a redução em $\psi_{\mathrm{h}}$. na estação seca, causada pela deficiência hídrica no solo, afetou negativamente as taxas fotossintéticas nas plantas, reduzindo a assimilação de $\mathrm{CO}_{2}$ e, consequentemente, a produção de fotoassimilados, diminuindo a produtividade potencial das plantas.

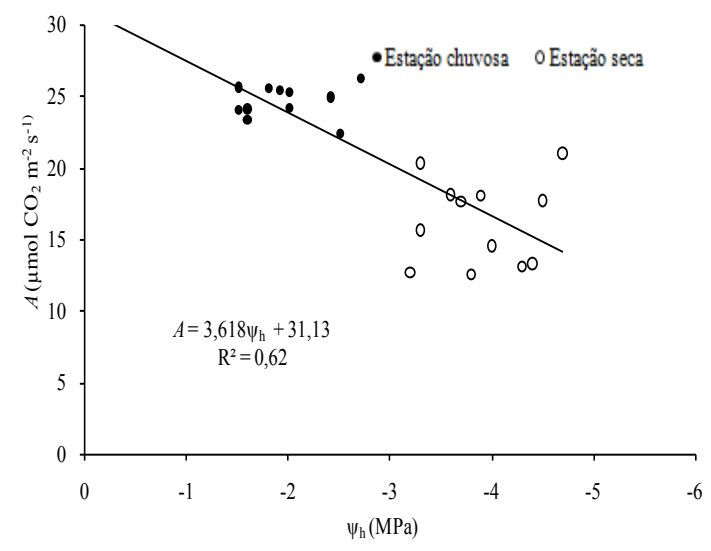

Figura 5. Regressão linear relacionando a fotossíntese $(A)$ às 10:00 $\mathrm{h}$ com o potencial hídrico antemanhã $\left(\psi_{\mathrm{h}}\right)$, em folhas de um plantio clonal de eucalipto, nas estações seca e chuvosa. 
Valadares et al. (2014) também relataram que a redução no $\psi_{\mathrm{h}}$ esteve associado com a queda de $A$ em cinco genótipos de eucalipto, promovida pela deficiência hídrica impostas por diferentes níveis de água no substrato.

Observa-se na Figura 6, que os valores de $A$ e $F_{\mathrm{m}}$ aumentaram linearmente quando se dispunha de um excedente hídrico no solo durante a estação chuvosa. Dessa forma, fica evidente que as condições prevalecentes na estação chuvosa contribuíram para aumento da eficiência de captação de energia luminosa pelo complexo antena do FS II, que por sinal, contribuíram para aumentos em $A$, quando comparado com as condições edafoclimáticas encontradas na estação seca.

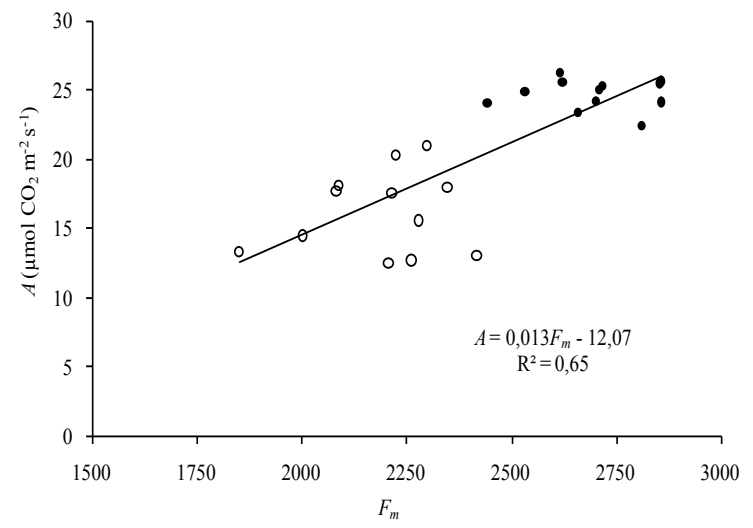

Figura 6. Regressão linear relacionando a fotossíntese $(A)$ às 10:00 horas com a fluorescência máxima $\left(F_{\mathrm{m}}\right)$, em folhas de um plantio clonal de eucalipto, nas estações seca e chuvosa.

Apesar do aumento linear encontrado na relação $A$ e $F_{\mathrm{m}}$, não houve relação entre $A$ e $F_{\mathrm{v}} / F_{\mathrm{m}}$ (Figura 7). Para $F_{\mathrm{v}} / F_{\mathrm{m}}$, os valores compreendidos entre 0,77 e 0,84 , obtidos nas duas estações, seca e chuvosa, estão dentro da faixa considerada como normal, entre 0,75-0,85 (CORREIA et al., 2014). A não detecção de aumentos na eficiência fotoquímica entre as plantas nas diferentes estações mostra que as reações do FS II não foram afetadas pela deficiência hídrica, ou seja, não ocorreu fotoinibição, muitas vezes considerada um dos efeitos do estresse hídrico (MOSETI; DINTWE, 2011). Estes resultados estão de acordo com os obtidos por Rolando e Little (2008) em mudas de E. grandis, e por Correia et al. (2014) em E. globulos submetidos ao estresse hídrico. Como esses autores ressaltaram, é possível concluir que a razão $F_{\sqrt{ }} / F_{\mathrm{m}}$ não reflete o estado de disponibilidade de água no solo disponível para as plantas.

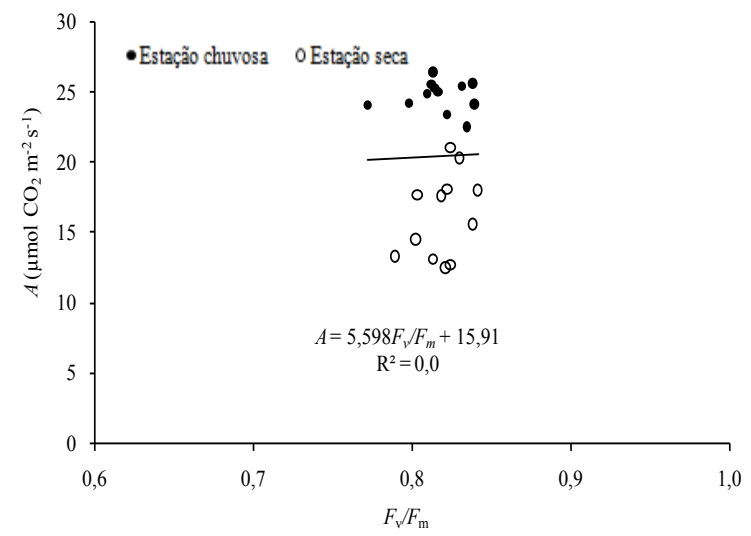

Figura 7. Regressão linear relacionando a fotossíntese $(A)$ às 10:00 $\mathrm{h}$ com a rendimento quântico máximo efetivo do FSII $\left(F_{\mathrm{v}} / F_{\mathrm{m}}\right)$, em folhas de um plantio clonal de eucalipto, nas estações seca e chuvosa.

\section{CONCLUSÕES}

- A deficiência hídrica no solo encontrada na estação seca foi suficiente para diminuir o teor de água nos tecidos vegetais das plantas de eucalipto, provocando redução em $g_{s}$ e, consequentemente, queda em $A$ e $E$. A menor abertura estomática durante estação seca contribuiu para queda na assimilação de carbono, diminuindo a produtividade potencial das plantas;

- A deficiência hídrica não causou danos no aparato fotossintético do FS II, como mostrado pelo razão $F_{\mathrm{v}} / F_{\mathrm{m}}$, mas reduziu a eficiência de captação de energia luminosa pelo complexo antena do FS II, reduzindo o fluxo de elétrons, o que pode ter contribuído para a redução em A.

\section{REFERÊNCIAS BIBLIOGRÁFICAS}

ADDINGTON, R.N.; MITCHELL, R.J.; DONOVAN, L.A. Stomatal sensitivity to vapor 
pressure deficit and its relationship to hydraulic conductance in Pinuspalustris. Tree Physiology, v.24, n.5, p. 561-569, 2004.

BOLHÀR-NORDENKAMPF, H.R.; LONG, S.P.; BAKER, N.R.; OQUIST, G.; SCHREIBER, U.; LECHNER, E.G. Chlorophyll fluorescence as probe of the photosynthetic competence of leaves in the field: a review of current instrument. Functional Ecology, v.3, p.497-514, 1989.

CAMARGO, A.P. Contribuição para a determinação da evapotranspiração potencial no Estado de São Paulo. Bragantia, v.21, p.163-203, 1962.

CORREIA, B. ; MARIJUAN-PINTÓ, M.; NEVES, L.; BROSSA, R.; DIAS, M.L.; COSTA, A.; CASTRO, B.B.; ARAÚJO, C.; SANTOS, C.; CHAVES, M.M.; PINTO, G. Water stress and recovery in the performance of two Eucalyptus globulus clones: physiological and biochemical profiles. Physiologia Plantarum, v.150, n.4, p.580-592, 2014.

DE LAS RIVAS, J.; BARBER, J. Structure and thermal stability of photo system II reaction centers studied by infrared spectroscopy. Biochemistry, v.36, p.8897-8903, 1997.

EMBRAPA. Centro Nacional de Pesquisa de Solos. Manual de métodos de análise de solo. 2. ed. Rio de Janeiro, 1997. 212p.

FIBRIA S.A. Dados climáticos, Aracruz: 2007 (Relatório interno).

FLOSS, E.L. Fisiologia das plantas cultivadas. 5 ed. Passo Fundo: 2011. 734p.

KOSLOWSKI, T.T.; PALLARDY, S.G. Physiology of woody plants. 2.ed. San Diego, 1996, 411p.

KRAUSE, G.H.; WEIS, E. Chlorophyll fluorescence and photosynthesis: the basics. Annual Review Plant Physiology. Plant Molecular Biology, v.42, p.313-349, 1991.
LARCHER, W. Ecofisiologia vegetal. 3 ed. São Carlos: Rima, 2004. 531p.

LEUNING, R.; CLEUGH, H.A.; ZEGELIN, S.J.; HUGHES, D. Carbon and water over a temperature Eucalyptus forest and a tropical wet/dry savanna in Australia: measurements and comparison with modis remote sensing estimates. Agricultural and Forest Meteorology, v.129, p.151-173, 2005.

MARRICHI, A.H.C. Caracterização da capacidade fotossintética e da condutância estomática em sete clones comerciais de Eucalyptus e seus padrões de resposta ao déficit de pressão de vapor. 2009. 104f. Dissertação (Mestrado em ????). Escola Superior de Agricultura "Luiz de Queiroz", Universidade de São Paulo. Piracicaba, SP. 2009.

MARTINS, F.B.; SILVA, J.C.; STERCK, N.A. Estimativa da temperatura-base para emissão de folhas e do filocrono em duas espécies de eucalipto na fase de muda. Revista Árvore, v.31, p.373-381, 2007.

MESKIMEN, G.; FRANCIS, J.K. Eucalyptus grandis Hill (ex. Maiden) Rose gum Eucalyptus. Disponível em: $<$ http://www.na.fs.fed.us/Spfo/ pubs/silvics_manual/volume_2/eucalyptus/ grandis.htm> Acesso em: 10 junho de 2014 .

MOSETI, B.; DINTWE, K. Effect of water stress on photosynthetic characteristics of two sorghum cultivars. The African Journal of Plant Science and Biotechnology, v.5, p.89-91, 2011. Special Issue.

OTTO, M.S.G.; VERGANI, A.R.; GONÇALVES, N.A.; VRECHI, A.; SILVA, R.S.; STAPE, J.S. Fotossíntese, condutância estomática e produtividade de clones de Eucalyptus sob diferentes condições edafoclimáticas. Revista Árvore, v.36, n.3, p.431-439, 2013.

PEREIRA, A.R.; ANGELOCCI, L.R.; SENTELHAS, P.C. Agrometeorologia: fundamentos e aplicações práticas. Guaíba: ed. Agropecuária, 2002. 478p. 
ROLANDO, C.A.; LITTLE, K.M. Measuring water stress in Eucalyptus grandis Hill ex Maiden seedlings planted into pots. South African Journal of Botany, v.74, n.1, p.13-138, 2008.

RYAN, M.G.; STAPE, J.L.; BINKLEY, D.; FONSECA, S.; LOOS, R.A.; TAKAHASHI, E.N.; SILVA, C.R.; SILVA, S.R.; HAKAMADA, R.R.; FERREIRA, J.M.; LIMA, A.M.N.; GAVA, J.L.; LEITE, F.P.; ANDRADE, H.B.; ALVES, J.M.; SILVA, G.C. Factors controlling Eucalyptus productivity: how water availability and stand structure alter production and carbon allocation. Forest Ecology and Management, v.259, n.9, p.1695-1703, 2010.

SCHOLANDER, P.F.; BRADSTREET, E.D.; HEMMINGSEN, E.A.; HAMMEL, H.T. Sap pressure in vascular plants. Science, v.148, n.3668, p.339-346, 1965.
TAIZ, L.; ZEIGER, E. Fisiologia Vegetal. Piracicaba: Ed. Artmed, 5. ed., 2013, 954p.

TATAGIBA, S.D.; PEZZOPANE, J.E.M.; FIALHO, E.F. Relações hídricas e trocas gasosas na seleção precoce de clones de eucalipto para ambientes com diferenciada disponibilidade de água no solo. Floresta, v.38, n.2, p.387-400, 2008.

TENHUNEN, J.D.; PEARCY, R.W.; LARANCE, O.L. Diurnal variation in leaf conductance gas exchange in natural environments. In: Zeiger, E., Farquhar, G.; Cowan, I (Ed.). Stomatal function. Stanford: Stanford University Press, 1987. p.323351.

VALADARES, J.; PAULA, N.F.; PAULA, R.C. Phssiological changes in eucalyptus hybrids under different irrigation regimes. Ciência Agronômica, v.45, n.4, p.805-814, 2014. 